\title{
Anabases
}

ANABASES Traditions et réceptions de l'Antiquité

15 | 2012

Varia

\section{Véronique KRINGS et Catherine VALENTI (dir.), Les Antiquaires du Midi. Savoirs et mémoires, XVI ${ }^{e}-X I X^{e}$ siècles}

\section{Germaine Aujac}

\section{OpenEdition}

\section{Journals}

Édition électronique

URL : http://journals.openedition.org/anabases/3824

DOI : 10.4000/anabases.3824

ISSN : 2256-9421

\section{Éditeur}

E.R.A.S.M.E.

\section{Édition imprimée}

Date de publication : 1 avril 2012

Pagination : 259-261

ISSN : $1774-4296$

\section{Référence électronique}

Germaine Aujac, « Véronique kRings et Catherine valenti (dir.), Les Antiquaires du Midi. Savoirs et mémoires, xvI -xIxe siècles ", Anabases [En ligne], 15 | 2012, mis en ligne le 01 avril 2012, consulté le 22 septembre 2020. URL : http://journals.openedition.org/anabases/3824 ; DOI : https://doi.org/ 10.4000/anabases.3824

Ce document a été généré automatiquement le 22 septembre 2020

(c) Anabases 


\title{
Véronique KRINGS et Catherine VALENTI (dir.), Les Antiquaires du Midi. Savoirs et mémoires, $X V I^{e}-X I X^{e}$ siècles
}

\author{
Germaine Aujac
}

\section{RÉFÉRENCE}

Véronique KRINGS et Catherine VALENTI (dir.), Les Antiquaires du Midi. Savoirs et mémoires, $X V I^{e}-X I X^{e}$ siècles, Paris, Errance, 2010, 192 p. +16 pl.

29 euros / ISBN 978-2-87772-443-2.

1 C'est un très bel ouvrage que présentent au lecteur les éditions Errance, écho d'une journée d'étude sur les Antiquaires du Midi qui s'est tenue au musée Saint-Raymond à Toulouse le 27 mars 2009. Aux contributions des participants ont été ajoutées celles de spécialistes qui complètent heureusement ce tour d'horizon.

2 Véronique Krings montre, dans une introduction très documentée (p. 7-10), le rôle qu'ont joué les «curieux d'antiquités» dans le développement de l'archéologie; elle souligne l'importance de l'essai fondateur d'Arnaldo Momigliano, « Ancient history and the Antiquarian », paru en 1950 dans le Journal of the Warburg and Courtauld Institutes 13 (p. 285-315).

3 Les contributions suivantes sont réparties sous deux rubriques. La première, « $\mathrm{Au}$ milieu des vestiges du passé ", nous conduit de Nîmes à Avignon, d'Orange à Arles et conclut par Narbonne. La seconde, « Des hommes, des objets et des savoirs ", présente les heurs et malheurs de l'archéologie en Catalogne française, évoquant quelques facettes de ce curieux personnage que fut Jean-François Perrot et rappelant l'étrange destinée d'Émile Espérandieu, cet officier passionné d'archéologie. Elle fait ensuite un détour par la région d'Autun. En guise de conclusion, Alain Schnapp indique les 
ressemblances et dissemblances entre antiquaires et archéologues et tire la substantifique moelle des articles du recueil.

4 Cette brève présentation ne saurait masquer la richesse d'exposés aussi érudits que variés, qui font revivre tant de personnages parfois injustement oubliés. C'est sur eux que je tournerai mon projecteur, en tentant de respecter un ordre chronologique. Le premier dans la liste est Jean-François Séguier (1703-1784), de Nîmes, qui avait constitué un cabinet d'antiquités et une bibliothèque remarquables, dont il fit don à sa ville, avec l'hôtel qui les abritait. Mais Nîmes a connu bien d'autres passionnés d'archéologie, comme le souligne François Pugnière (p.13-29). Louis Chapat (1707-1784), qui fut "un revêche magistrat de Berlin", au dire d'Odile Cavalier (p. 53-72), mais aussi un conseiller du roi de Prusse, légua lui aussi à sa ville natale d'Orange son cabinet portatif, riche d'un millier de monnaies. Il est vrai qu'à Avignon, Esprit Calvet (1728-1810), un médecin, en avait réuni plusieurs milliers dans son cabinet de curiosités dont, une fois encore, Odile Cavalier nous dévoile les richesses si diverses (p. 31-52).

5 À Perpignan, François Jaubert de Passa (1785-1856) étudiait les monuments des Pyrénées orientales et pouvait discuter avec Prosper Mérimée de l'origine, si controversée, de la curieuse église de Planès, dont une lithographie ornait le Voyage pittoresque au département des Pyrénées orientales du chevalier de Basterot, paru en 1824. Olivier Poisson conclut son étude («Des antiquaires à l'archéologie monumentale catalane », p. 99-116) en évoquant l'intérêt soutenu porté par le Gascon Jean-Auguste Brutails (1859-1926) à l'art religieux du Roussillon.

6 Jean-François-Aimé Perrot (1790-1867), né à Alès mais mort à Paris, a suscité l'intérêt de Christian Landes (p. 117-130), qui le présente comme un "Grognard » autodidacte, ardent défenseur de Jean-François Séguier dont il se voulait l'héritier. Sydney $\mathrm{H}$. Aufrère et Alain Dautant (p.131-159) décrivent à leur tour son intérêt pour l'égyptologie (il est pour eux l'« égyptologue d'un jour »). Enrôlé dans la Grande Armée, il avait servi successivement en Autriche, Russie, Italie, puis était revenu à Nîmes. Chargé de diriger les fouilles autour des monuments antiques, il devint bientôt gardien de la Maison carrée. L'acquisition en 1829 d'une momie égyptienne devait lui donner le goût (sans la science) de l'égyptologie.

7 Renaud Robert et Danièle Terrer intitulent leur exposé "Émile Espérandieu et l'utilisation des sources iconographiques tirées des antiquaires»(p.161-171). Ce brillant Saint-Cyrien (1857-1939), né dans le Gard et qui termina sa vie à Avignon, fut un grand collectionneur de manuscrits, mais aussi l'auteur d'un Recueil général des basreliefs, statues et bustes de la Gaule romaine, illustré de nombreuses photographies prises par lui-même.

8 Les autres articles, sans présenter des personnages aussi hauts en couleur, témoignent de l'intérêt nouveau suscité par les antiquités. Estelle Rouquette (« De la passion du sol à la science : antiquaires arlésiens et archéologues au XIX ${ }^{\mathrm{e}}$ siècle », p. 73-85) montre que le véritable musée archéologique d'Arles reste la ville elle-même, théâtre de son passé. Pour Chantal Alibert («Les antiquaires narbonnais à l'origine de la politique patrimoniale de Narbonne », p. 87-96), la commission archéologique créée au xix siècle prenait le relais des érudits des siècles précédents. Cela n'allait pas sans heurts, comme l'indique Pierre Pinon dans «Les antiquaires autunois vus par Harold de Fontenay (Autun et ses monuments, 1889) ». Cet élève de Jules Quicherat, né et mort à Autun (1841-1889), auteur d'une géographie comparée sur le territoire de l'ancien diocèse 
d'Autun, quoique utilisant de nombreuses sources puisées chez les antiquaires, reprochait à ceux-ci de n'être que des collectionneurs incultes, alors que les archéologues savaient replacer les objets dans leur contexte historique, offrant à leurs successeurs la possibilité de vérifier, de comparer et de continuer le travail.

9 Seize pages en couleur, séparant les deux parties du recueil, illustrent magnifiquement certains articles et ajoutent à l'intérêt de cet ouvrage. Un index complet permet de retrouver les indications données sur tel ou tel personnage.

10 On ne saurait trop conseiller aux spécialistes des antiquités, mais aussi à tout amateur intéressé par l'histoire - et par ceux qui la font-, la lecture de cet ouvrage plein d'agrément et aussi varié qu'érudit. Comme le souligne pertinemment A. Schnapp dans sa conclusion, «la transformation du savoir antiquaire en science archéologique a été un long et difficile combat... Le mérite du présent ouvrage est de nous donner les moyens d'entendre et de comprendre ce processus singulier de fondation scientifique " (p. 190).

\section{AUTEURS}

GERMAINE AUJAC

Université de Toulouse (UTM)

aujac.germaine@wanadoo.fr 